\title{
BMJ Open COVID-19 in Oromia Region of Ethiopia: a review of the first 6 months' surveillance data
}

Esayas Kebede Gudina (1) , ${ }^{1}$ Dabesa Gobena, ${ }^{2}$ Tessema Debela, ${ }^{2}$ Daniel Yilma, ${ }^{1}$ Tsinuel Girma, ${ }^{3}$ Zeleke Mekonnen, ${ }^{4}$ Mirkuzie Woldie, ${ }^{3}$ Dereje Abdena, ${ }^{5}$ Gemechu Shume, ${ }^{6}$ Birhanu Kenate, ${ }^{7}$ Meles Lemi, ${ }^{2}$ Dereje Diriba, ${ }^{2}$ Tizta Tilahun Degfie (1D) ${ }^{3,8}$

To cite: Gudina EK, Gobena D, Debela T, et al. COVID-19 in Oromia Region of Ethiopia: a review of the first 6 months' surveillance data. BMJ Open 2021;11:e046764. doi:10.1136/ bmjopen-2020-046764

- Prepublication history for this paper is available online. To view these files, please visit the journal online (http://dx.doi. org/10.1136/bmjopen-2020046764).

Received 10 November 2020 Revised 10 March 2021 Accepted 15 March 2021
Check for updates

(C) Author(s) (or their employer(s)) 2021. Re-use permitted under CC BY-NC. No commercial re-use. See rights and permissions. Published by BMJ.

For numbered affiliations see end of article.

Correspondence to Professor Esayas Kebede Gudina; esakgd@gmail.com

\section{ABSTRACT}

Introduction Despite unrelenting efforts to contain its spread, COVID-19 is still causing unprecedented global crises. Ethiopia reported its first case on 13 March 2020 but has an accelerated case load and geographical distribution recently. In this article, we described the epidemiology of COVID-19 in Oromia Region, the largest and most populous region in Ethiopia, during the early months of the outbreak.

Methods We analysed data from the COVID-19 surveillance database of the Oromia Regional Health Bureau. We included all reverse transcription-PCRconfirmed cases reported from the region between 13 March and 13 September 2020.

Results COVID-19 was confirmed in 8955 (5.5\%) of 164206 tested individuals. The test positivity rate increased from an average of $1.0 \%$ in the first 3 months to $6.3 \%$ in August and September. About $70 \%(6230)$ of the cases were men; the mean age was 30.0 years $(S D=13.3)$, and $90.5 \%$ were $<50$ years of age. Only $64(0.7 \%)$ of the cases had symptoms at diagnosis. Cough was the most common among symptomatic cases reported in $48(75.0 \%)$, while fever was the least. Overall, $4346(48.5 \%)$ have recovered from the virus; and a total of 52 deaths were reported with a case fatality rate of $1.2 \%$. However, we should interpret the reported case fatality rate cautiously since in $44(84.6 \%)$ of those reported as COVID-19 death, the virus was detected from dead bodies. Conclusion Despite the steady increase in the number of reported COVID-19 cases, Ethiopia has so far avoided the feared catastrophe from the pandemic due to the milder and asymptomatic nature of the disease. However, with the current pattern of widespread community transmission, the danger posed by the pandemic remains real. Thus, the country should focus on averting COVID19-related humanitarian crisis through strengthening COVID-19 surveillance and targeted testing for the most vulnerable groups.

\section{INTRODUCTION}

No other pandemic has ever affected the world to such a scale in a short time than COVID-19. Since the first official report
Strengths and limitations of this study

- It is the first comprehensive report on the COVID-19 outbreak from Ethiopia.

- The epidemiological trends and clinical profile of cases collected based on the WHO's COVID-19 surveillance guideline have been presented.

- We included all reverse transcription-PCR-positive cases diagnosed in the region during the first 6 months' surveillance period.

- The clinical course of patients during follow-up was not assessed.

- The reported mortality and hence the case fatality rate may not reflect the reality on the ground.

in December 2019, COVID-19 has spread to 216 countries and territories in the first 8 months, infected over 25 million people and resulted in close to 850000 fatalities. ${ }^{1}$

Egypt reported the first case of COVID-19 in Africa on 14 February 2020, ${ }^{2}$ and on 27 February 2020, Nigeria reported the first case from sub-Saharan Africa. ${ }^{3}$ Although the figure reported from Africa has remained small compared with the rest of the world, the number of confirmed cases has gradually increasing over the past few months. Moreover, the low number of cases in the continent is likely to be linked to the late arrival of the disease in Africa, and that only a small proportion of cases were tested and diagnosed. ${ }^{45}$

Ethiopia reported its first case on 13 March 2020, and the number of reported cases has shown a slow but steady increase ever since. It took 79 days to reach the first 1000 cases, but this number doubled in the next 9 days. Recent reports of a large cluster of cases from Addis Ababa, capital city of Ethiopia, and other towns across the nation show the presence of widespread community transmission of the virus. ${ }^{6} 7$ 
COVID-19 has a relatively low case fatality rate (CFR) as compared with many other pandemic diseases. ${ }^{8}$ However, it spreads much faster than most other outbreaks and may ultimately cause more deaths. ${ }^{9}$ Data from Europe and North America show an exponential spread of the disease ${ }^{10}$ with the rapid increase in the number of cases and deaths. ${ }^{7}$ The full picture of the pandemic in most lowincome and middle-income countries remains obscure due to limited data. ${ }^{11}$

Despite unrelenting global efforts to contain the spread of COVID-19, the pandemic is still causing unprecedented crises across the world. ${ }^{12}{ }^{13}$ Short of the most lethal weapon for prevention and treatment, ${ }^{14}$ every country has resorted to a trial-and-error approach to keep the balance of safeguarding the health of its citizens and saving the economy. ${ }^{15}$ Most African countries braced themselves for the worstcase scenario and took the most stringent actions preemptively. ${ }^{16}$ However, 7 months into the pandemic, the outbreak has not hit the continent as much as it was feared. ${ }^{17}$ Yet, the collateral damage to the healthcare system and other sectors is causing more crises than the continent could handle. ${ }^{18}$ Thus, control measures against the pandemic's risk should be balanced based on robust local evidence. This paper described the epidemiology, transmission dynamics and clinical characteristics of COVID-19 cases in the Oromia Region, Ethiopia, based on the first 6 months' surveillance data.

\section{METHODS}

\section{Study setting and design}

Oromia is the largest and most populous region of the 10 regional states in Ethiopia. Based on the Population and Housing Census in 2007, the region's population is projected to be 38 million by 2020 , accounting for nearly $35 \%$ of the Ethiopian population; $87.7 \%$ are rural residents. Administratively, the region is divided into 21 zones, 19 town administrations, 317 districts and 7011 kebeles (the smallest administrative unit in Ethiopia). The region accounts for $32 \%$ of Ethiopian land size with an area of $363399.8 \mathrm{~km}^{2} .{ }^{19}$

This study was based on analysis of the COVID-19 surveillance database of the Oromia Regional Health Bureau. All reverse transcription (RT)-PCRconfirmed COVID-19 cases diagnosed at COVID-19 diagnostics facilities across the region from 13 March to 13 September 2020 were included in this analysis. Residents of the region who were tested outside the region were also included in this analysis.

\section{Case definitions}

Cases were defined based on the WHO's and/or national guideline as follows:

\begin{tabular}{|c|c|}
\hline $\begin{array}{l}\text { Conditions/ } \\
\text { terminologies }\end{array}$ & Definitions \\
\hline $\begin{array}{l}\text { Suspected } \\
\text { COVID-19 case }\end{array}$ & $\begin{array}{l}\text { Any person presenting with an acute } \\
\text { onset of fever AND cough; OR ANY } \\
\text { THREE OR MORE of the following signs } \\
\text { or symptoms: fever, cough, general } \\
\text { weakness/fatigue, headache, myalgia, } \\
\text { sore throat, coryza, dyspnoea, anorexia/ } \\
\text { nausea/vomiting and diarrhoea } 2021\end{array}$ \\
\hline Close contact & $\begin{array}{l}\text { Face-to-face contact within } 2 \mathrm{~m} \text { for more } \\
\text { than } 15 \text { min OR direct physical contact } \\
\text { with a confirmed COVID-19 case within } \\
14 \text { days of symptom onset or positive } \\
\text { test }^{20} 21\end{array}$ \\
\hline $\begin{array}{l}\text { First-generation } \\
\text { cases }\end{array}$ & $\begin{array}{l}\text { Those with a clear history of recent } \\
\text { international travel and assumed to be } \\
\text { imported cases }\end{array}$ \\
\hline $\begin{array}{l}\text { Second- } \\
\text { generation cases }\end{array}$ & $\begin{array}{l}\text { Those with a clear history of contact with } \\
\text { first-generation or confirmed cases }\end{array}$ \\
\hline $\begin{array}{l}\text { Third-generation } \\
\text { cases }\end{array}$ & $\begin{array}{l}\text { Cases with neither clear history of } \\
\text { contact nor recent travel }\end{array}$ \\
\hline $\begin{array}{l}\text { Asymptomatic } \\
\text { COVID-19 }\end{array}$ & $\begin{array}{l}\text { No reported symptom by the patient } \\
\text { PLUS normal findings on initial physical } \\
\text { examination }^{21}\end{array}$ \\
\hline Mild COVID-19 & $\begin{array}{l}\text { Uncomplicated upper respiratory tract } \\
\text { infections }^{21}\end{array}$ \\
\hline $\begin{array}{l}\text { Moderate } \\
\text { COVID-19 }\end{array}$ & $\begin{array}{l}\text { Mild pneumonia not needing } \\
\text { supplemental oxygen or breathing } \\
\text { difficulty }^{21}\end{array}$ \\
\hline Severe COVID-19 & $\begin{array}{l}\text { Severe pneumonia OR acute respiratory } \\
\text { distress syndrome }\end{array}$ \\
\hline Critical & $\begin{array}{l}\text { Any of the following conditions: } \\
\text { respiratory failure, septic shock, multiple } \\
\text { organ dysfunctions or failure and need for } \\
\text { invasive or special management }^{21}\end{array}$ \\
\hline
\end{tabular}

\section{Case identification and testing}

The surveillance was conducted based on the WHO's COVID-19 surveillance guideline ${ }^{20}$ customised to the local setting. Nasopharyngeal specimens were collected from clinically suspected cases, contacts of confirmed cases, international arrivals, high risks and vulnerable groups in the community. The laboratory test was performed as per the WHO guideline for laboratory testing of COVID-19 $9^{22}$ and the Interim National Strategy and Guidance for the Laboratory Diagnosis of COVID-19 in Ethiopia. ${ }^{23}$ RT-PCRconfirmed cases were traced by the regional surveillance team from the laboratory sample collection database and linked to the rapid response team (RRT). The RRT conducted individual case investigation and linked the cases to COVID-9 treatment centres by ambulances designated for this purpose only.

\section{Clinical outcome}

We followed outcome data until 13 September 2020. The outcome was classified based on the national guideline ${ }^{21}$ as a recovered case or death. COVID-19 case was declared as recovered if the patient had two consecutive negative 
RT-PCR tests 24 hours apart. In this surveillance data, a COVID-19 death was reported as a death occurring in a confirmed COVID-19 case or if the COVID-19 was confirmed from a dead body no matter what the cause of the death might be. ${ }^{21}$

CFR was calculated based on the WHO's recommendation for estimating mortality from COVID- $19^{24}$ as:

$$
\begin{aligned}
& \text { Case Fatality Ratio (CFR, in \%) } \\
& =\frac{\text { Number of deaths from the disease }}{\text { Number of deaths from the disease }+ \text { Number of recovered from the disease }} \times 100
\end{aligned}
$$

All confirmed cases along with demographic and clinical data were reported via line-list format by individual variables.

\section{Data management and analysis}

The aggregated data originally in Microsoft Excel format were cleaned, coded and exported to STATA software V.16 for analysis. Analyses began with characterising the disease's pattern by person, place, time and other variables. We computed COVID-19 incidence using the number of cases over the period (days, weeks and months).

To estimate the transmissibility of COVID-19 in this study, we figured the reproduction number by classifying sources of infection as imported cases, cases with close contacts and cases with no clear contact. ${ }^{25}$ Hence, the reproduction ratio $\left(\mathrm{R}_{0}\right)$ for this study was calculated using the following formula.

$$
\begin{aligned}
& R_{01}=\frac{\text { Number of cases with clear contacts }}{\text { Number of cases with clear travel history }(\text { imported })} \\
& R_{02}=\frac{\text { Number of cases with no clear contact }(\text { community) }}{\text { Number of cases with clear contact }}
\end{aligned}
$$

We calculated the effective reproductive rate $\left(\mathrm{R}_{\mathrm{e}}\right)$ making the following assumptions: imported case as firstgeneration, contact as second-generation and community as the third-generation.

$$
R_{e}=R_{0} \times S
$$

Where $\mathrm{R}_{0}$ corresponds to the basic reproduction ratio, and $\mathrm{S}$ corresponds to the proportion of susceptible individuals in the population. The proportion of susceptible (S) is those who are not infected; however, they could potentially become infected. ${ }^{26}$

Ethiopia reported 64301 cases by 13 September 2020 among an estimated population of $115738799 .{ }^{7}$ With the current test positivity rate of $5.5 \%$, we assumed that about $5.5 \%$ of the Ethiopian population had been infected. Thus, the proportion of the susceptible population was 0.945 .

We also applied the spatial distribution using a heatmap to show COVID-19 infection across the region. We applied different colours to show the graduated scale using natural breaks with four classes.

\section{Patient and public involvement}

There was no direct public involvement either in the setting of the research questions or in developing the study design because it was not feasible given the available time and funding.

\section{RESULTS \\ Sociodemographic characteristics, clinical profiles and discharge outcomes}

Among 8955 RT-PCR-confirmed COVID-19 cases included in this analysis, $69.6 \%$ were men. The mean age was 30.0 years $(\mathrm{SD}=13.3$ ) with a range of 18 days -96 years; $87.8 \%$ were between 10 and 49 years of age at COVID-19 diagnosis. Overall, $4932(55.1 \%)$ of the cases were rural residents (table 1 ).

Only $64(0.7 \%)$ reported symptoms at the time of diagnosis. Cough was the most common symptom reported in $75.0 \%$ ( 48 of 64 ) of the cases, while fever was the least common (figure 1). Only 9.4\% (6 of 64) of those reporting symptoms on diagnosis had severe symptoms (hence classified as severe cases); $48(75.0 \%)$ had mild symptoms. Twelve $(0.1 \%)$ cases had sought treatment for COVID-19-related symptoms before their diagnosis. Fourteen $(0.2 \%)$ had known underlying medical conditions; eight of those with comorbidities had either hypertension or bronchial asthma or both (table 1).

On this analysis, $4346(48.5 \%)$ have recovered from the infection, while $52(0.6 \%)$ have died with the CFR of $1.2 \%$ (52 of 4398). Among the deaths, 37 died in the community and the virus was detected during postmortem examination. Seven patients were being treated at health facilities for other medical conditions and were tested as part of routine screening of hospitalised patients. However, the result of the COVID-19 test was released after the patients passed away. Only eight of the deaths happened in patients being treated as COVID-19 cases (table 1). Of the patients who died before being admitted to COVID-19 care centres (44 cases), only five (11.4\%) had COVID-19-like symptoms. Furthermore, among 64 cases who had symptoms before diagnosis, 8 $(12.5 \%)$ have passed away.

Twelve $(23.1 \%)$ of the deaths occurred in those 60 years and older even though they constituted for only $4.2 \%$ of the total cases; the CFR in this group was $7.2 \%$. The second highest CFR (2.9\%) was recorded among under-5 children, and the lowest $(0.4 \%)$ was in the age group of 10-19years (figure 2).

\section{Epidemiological characteristics}

Most of the cases, $8481(94.7 \%)$, were detected through community surveillance, and $320(3.6 \%)$ were identified from isolation/quarantine centres; $22(0.2 \%)$ were diagnosed among people visiting health facilities for COVID19-like symptoms. In terms of the source of infection, we could trace the possible source for only 1642 (18.2\%) cases: $1463(16.3 \%)$ were close contacts of confirmed cases while 169 (1.9\%) were imported cases. Most of the imported cases were either from East African countries, 104 (61.5\%), or the Middle East, 50 (29.6\%) (table 2). 
Table 1 Demographic and clinical characteristics of cases diagnosed with COVID-19 in Oromia Region, Ethiopia

\begin{tabular}{lcc}
\hline \multicolumn{1}{|c}{$\begin{array}{l}\text { Frequency } \\
\text { (N=8955) }\end{array}$} & \% \\
\hline Sex & & \\
$\quad$ Male & 6230 & 69.6 \\
\hline Female & 2725 & 30.4 \\
\hline Age & & \\
\hline$<10$ & 258 & 2.9 \\
\hline $10-19$ & 961 & 10.7 \\
\hline $20-29$ & 4013 & 44.9 \\
\hline $30-39$ & 1979 & 22.1 \\
\hline $40-49$ & 900 & 10.1 \\
\hline $50-59$ & 471 & 5.3 \\
\hline$\geq 60$ & 373 & 4.2 \\
\hline Residence & & \\
\hline Urban & 3947 & 44.1 \\
\hline Rural & 4932 & 55.1 \\
\hline Unknown/missing & 76 & 0.8 \\
\hline
\end{tabular}

Have sought treatment for COVID-19-related symptoms before diagnosis

\begin{tabular}{|c|c|c|}
\hline Yes & 12 & 0.1 \\
\hline No & 8943 & 99.9 \\
\hline \multicolumn{3}{|l|}{ Had known underlying medical condition } \\
\hline Yes & 14 & 0.2 \\
\hline No & 8941 & 99.8 \\
\hline \multicolumn{3}{|l|}{ Symptomatic } \\
\hline Yes & 64 & 0.7 \\
\hline No & 8891 & 99.3 \\
\hline \multicolumn{3}{|l|}{ Severity of the disease $(n=64)^{\star}$} \\
\hline Mild & 48 & 75.0 \\
\hline Moderate & 10 & 16.0 \\
\hline Severe & 6 & 9.0 \\
\hline \multicolumn{3}{|l|}{ Current status } \\
\hline On follow-up/treatment & 4557 & 50.9 \\
\hline Recovered & 4346 & 48.5 \\
\hline Died & 52 & 0.6 \\
\hline \multicolumn{3}{|l|}{ Place of death $(n=52)$} \\
\hline Community (outside health facility) & 37 & 71.2 \\
\hline At health facility & 7 & 13.5 \\
\hline At COVID-19 treatment centre & 8 & 15.4 \\
\hline
\end{tabular}

*Forty-four patients died before diagnosis of COVID-19; the virus was detected from dead body (37 cases) and specimen collected before their death (7 cases). COVID-19-related symptoms were reported in only five of them.

\section{Disease transmission rate}

Considering imported cases as the first-generation $(\mathrm{n}=169)$, contact as second-generation $(\mathrm{n}=1463)$ and community as the third-generation $(n=7323)$, the basic reproduction ratio $\left(\mathrm{R}_{0}\right)$ was estimated to be 8.7

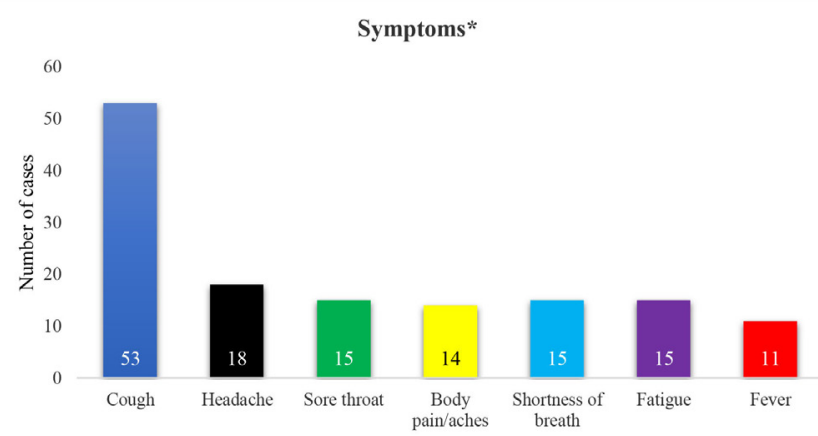

Figure 1 Common symptoms among symptomatic COVID-19 cases in Oromia Region, Ethiopia. *Twentyone had two or more symptoms; cough with shortness of breath and cough with sore throat were the most common combination (13 each), followed by cough with fever (10).

(1463/169) for imported cases and $5.0(7323 / 1463)$ for contacts in the community.

From these assumptions, the effective reproduction ratios $\left(R_{e}\right)$ calculated for the first to the second-generation transmission and for the second to third-generation transmission were estimated to be 8.2 and 4.7 , respectively.

Laboratory tests, performance and patterns of case detection A total of 164206 individuals were tested with RT-PCR for SARS-CoV-2 during the surveillance period and 8955 $(5.5 \%)$ were confirmed with the infection. Most of the laboratory tests, 128210 (78.1\%), were performed in the last 6 weeks of the surveillance. Similarly, even though this surveillance data involved analysis of the 25 weeks since the first case of COVID-19 in Ethiopia, $84.1 \%$ of the cases were diagnosed in the last 6 weeks only. The average number of daily tests in the region increased from around 200 during the period of April-June 2020 to more than 4000 in August and September 2020. The test positivity rate also increased from an average of $1.0 \%-6.3 \%$ during these two periods, respectively (figure 3 ).

With regard to geographical distribution of the cases, all 21 zones and 19 town administrations in the region have been affected. However, most of the cases were concentrated in the central part of the region around the capital

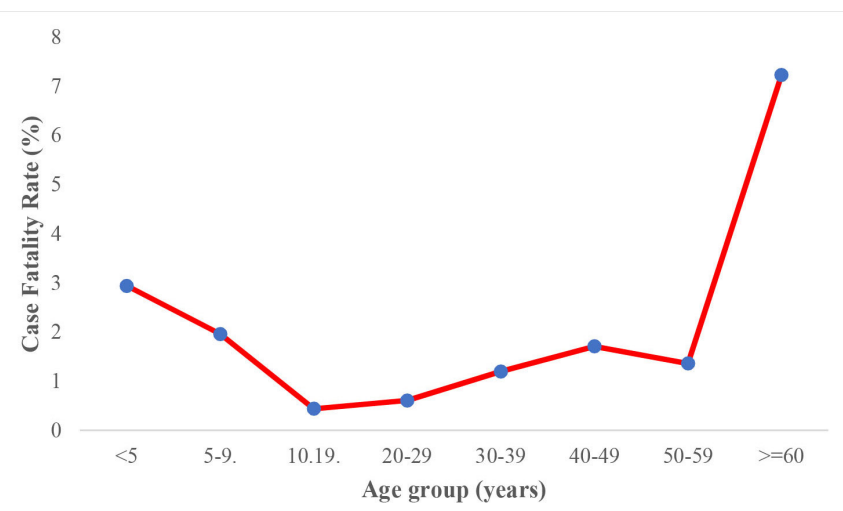

Figure 2 Case fatality by age group among COVID-19 cases in Oromia Region, Ethiopia. 
Table 2 Sources of cases and infection for confirmed COVID-19 cases in Oromia Region, Ethiopia

\begin{tabular}{lrr}
\hline & $\begin{array}{c}\text { Frequency } \\
\text { (N=8955) }\end{array}$ & \multicolumn{1}{c}{$\%$} \\
\hline Source of cases (case detection method) & \\
\hline Community surveillance & 8481 & 94.7 \\
\hline Isolation/quarantine centres & 320 & 3.6 \\
\hline Screening at health facility & 108 & 1.2 \\
\hline Contact tracing & 24 & 0.3 \\
\hline Testing of clinically suspected cases & 22 & 0.2 \\
\hline Source of infection & 7323 & \\
\hline Community transmission & 1463 & 4.9 \\
\hline Contact of confirmed case & 169 & 1.9 \\
\hline Imported & & \\
\hline Origin of imported cases ( $\mathrm{n=169)}$ & 104 & 61.5 \\
\hline East Africa & 50 & 29.6 \\
\hline Middle East & 2 & 1.2 \\
\hline Others & 13 & 7.7 \\
\hline Unknown & & \\
\hline
\end{tabular}

city, Addis Ababa. Additionally, there was clustering of the cases in urban settings throughout the region (figure 4).

\section{DISCUSSION}

Nearly 9000 RT-PCR-confirmed COVID-19 cases were reported in Oromia Regional state during the first 6 months of the surveillance period. Most of the cases were $<50$ years of age. Very few cases were symptomatic at the time of diagnosis; cough was commonly reported in those presenting with symptoms. A CFR of $1.2 \%$ was reported among closed cases. However, the reported mortality also included deaths due to other conditions but in whom the virus was detected. The average test positivity rate increased from $<1 \%$ during the first 3 months to $>5 \%$ in the last few weeks. Even though we have included all RT-PCR-confirmed cases, we could not elucidate the transmission dynamics and geographical distribution of cases in the region with certainty due to inconsistent and limited surveillance and testing. However, there was clear clustering of cases in urban settings with widespread community transmission.

Ethiopia acquired its first COVID-19 testing facility on 8 February $2020 .^{27}$ Since then, the testing capacity has increased and gradually rolled out throughout the country. This increased testing capacity and geographical coverage could partly explain the sustained increase in the number of cases. However, the gradual increase in the test positivity rate from $1 \%$ during the first 3 months of the outbreak to more than 6\% in August and September shows a steady increase in community transmission.

Testing is a vital feature of an effective surveillance system. ${ }^{28}$ Still, the lack of consistent and widespread access to testing within and between the regions complicates the meaningful interpretation of national and subnational data. Oromia acquired the first COVID-19 testing facility as of 30 April 2020. However, testing capacity was scaled up only in August as part of a new national campaign called Enhanced Community-based Activities and Testing (ComBAT). Following the implementation of ComBAT, the region's testing capacity increased by 20 -fold within a month of the initiative. The test positivity rate also increased by 18.5-fold in August as compared with April and May 2020. Thus, the marked increase in the number of cases recently could be due to both improved testing and widespread community transmission of the disease.

Social factors also challenged the COVID-19 surveillance and control activities in Oromia. For instance, during the first 2 weeks of July, most testing facilities in the region did not perform adequate tests due to community unrest. Moreover, during the unrest, the protesters gathered in large crowds with no social distancing and use of masks. It is thus likely that the surge in the number of cases and test positivity rates since late July is partly attributable to these factors.

Despite the surge in the number of cases, the humanitarian crisis due to the pandemic remains much less than initially feared. During the early few weeks of the pandemic in Wuhan, China, COVID-19 was reported as a predominantly symptomatic disease, with fever and cough being reported in most cases. ${ }^{29}{ }^{30}$ However, as the pandemic evolved and spread worldwide and with enhanced blanket testing in many countries, the proportion of asymptomatic cases has gradually increased. Since March, data from China, Europe and North America have shown that more than half of RT-PCR-confirmed cases were asymptomatic. ${ }^{31-34}$ However, the proportion of asymptomatic cases in our report is much higher than most of the published reports so far. ${ }^{31} 3334$

According to this surveillance, the rates of symptomatic and severe disease at initial diagnosis were $0.7 \%$ (64 cases) and $0.1 \%$ (6 cases), respectively. Multiple factors can explain the reason for the low proportion of symptomatic cases and severe disease. First of all, $87.8 \%$ of the patients were between ages 10 and 49 years, and only $4.2 \%$ were 60 years or older. Thus, as reported from different countries show, younger people are likely to be asymptomatic and to have milder disease.$^{356}$ Besides, only $14(0.2 \%)$ of the patients had known underlying medical conditions.

Although SARS-CoV-2 is a new human pathogen, few studies have shown that conditions eliciting non-specific immune response such as BCG vaccination ${ }^{37} 38$ and recurrent parasitic infections ${ }^{39}$ may render some protection against COVID-19. Thus, widespread routine BCG vaccination and rampant parasitic infections in communities in Ethiopia and other African countries might have contributed to milder COVID-19 in such settings.

It is also possible that patients and even healthcare providers may overlook milder and atypical symptoms of COVID-19 at initial evaluation. For instance, we did not report loss of smell and taste at all in this surveillance. These symptoms and other milder conditions that do not 


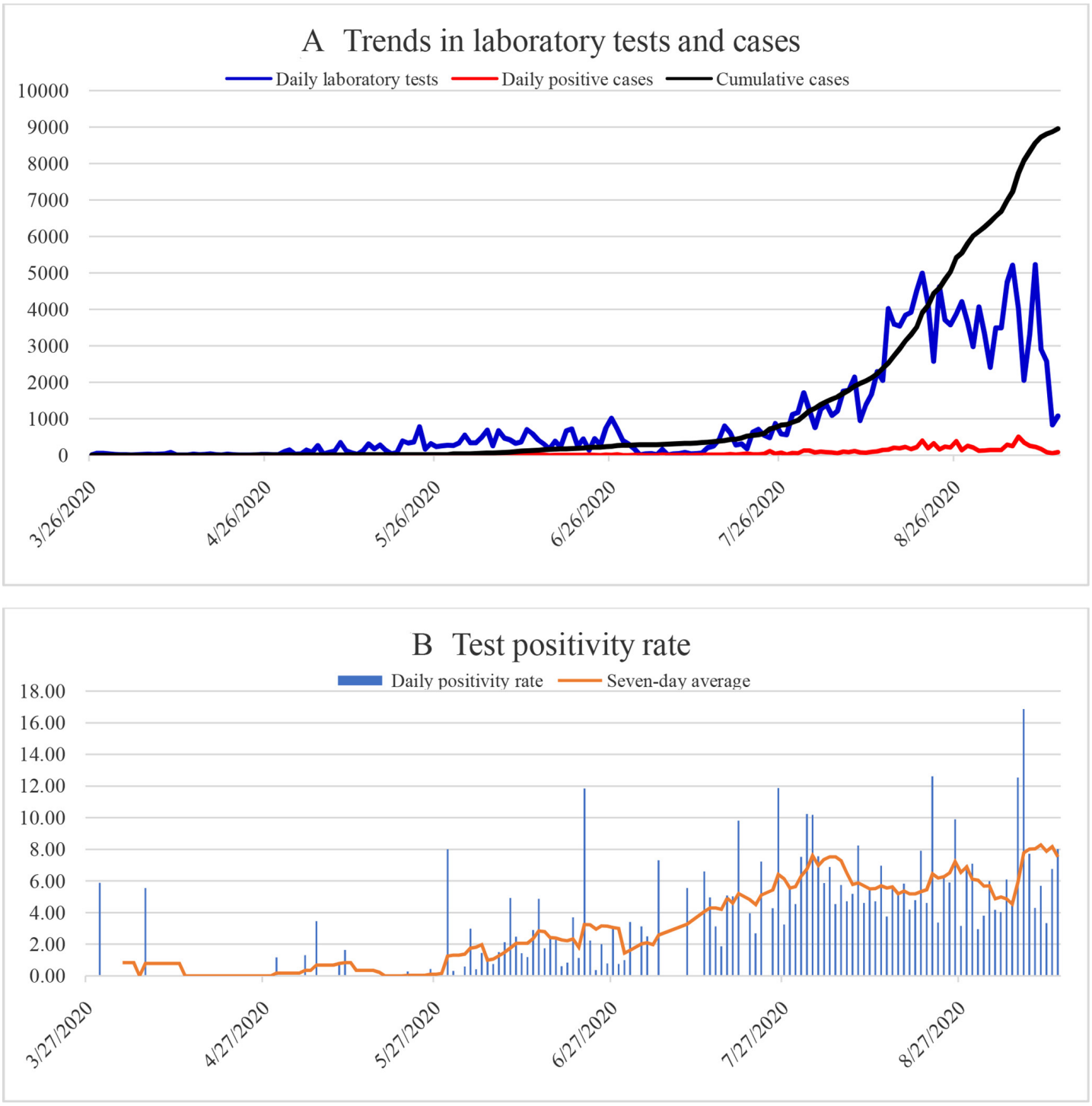

Figure 3 Trends in laboratory tests (A) and test positivity rate (B) of COVID-19 in Oromia Region, Ethiopia.

often impair the individual's functionality can easily be ignored by the patients unless actively pursued during the interview. Moreover, as $84 \%$ of the cases were healthy individuals detected during active community surveillance, most of them possibly did not undergo proper clinical evaluations. Besides, as this surveillance data did not include clinical courses during the follow-up period, it is possible that some of the cases might have developed symptoms after diagnosis.

Similarly, the low rate of comorbidities is also due to how the data were collected. As the assessment for underlying medical conditions was based only on patients' self-report, it might have missed many people with comorbidities on admission. Thus, proactive and contextualised clinical screening is essential to detect subtle symptoms of COVID-19 and concealed underlying medical conditions in all confirmed cases.

On the other hand, although the reported CFR of $1.2 \%$ is lower than the recent global estimate of $3 \%,{ }^{40}$ we still believe that the reported CFR is potentially an overestimation and highly inaccurate. The Ethiopian national COVID-19 management protocol indiscriminately categorises all deaths as COVID-19 death if the virus is detected from a dead body no matter what the immediate cause of the death is. ${ }^{21}$ In our report, of the 52 deaths, only 8 were attributable to COVID-19. The rest 44 died before the COVID-19 diagnosis was made, and 37 of these deaths happened in the community. It is thus difficult to attribute most of those deaths directly to COVID-19. On the other hand, it is also possible that COVID-19-related deaths were under-reported due to inadequate surveillance and limited testing capacity. Hence, the real case fatality due to the pandemic in the region remains obscure.

Nevertheless, it may be safe to conclude that Ethiopia, like other African countries, has not so far suffered from the 'tsunami' of COVID-19 cases and deaths. The very high rate of the asymptomatic case and low CFR observed compared with reports from many high-income settings are the possible reasons for this. However, asymptomatic 


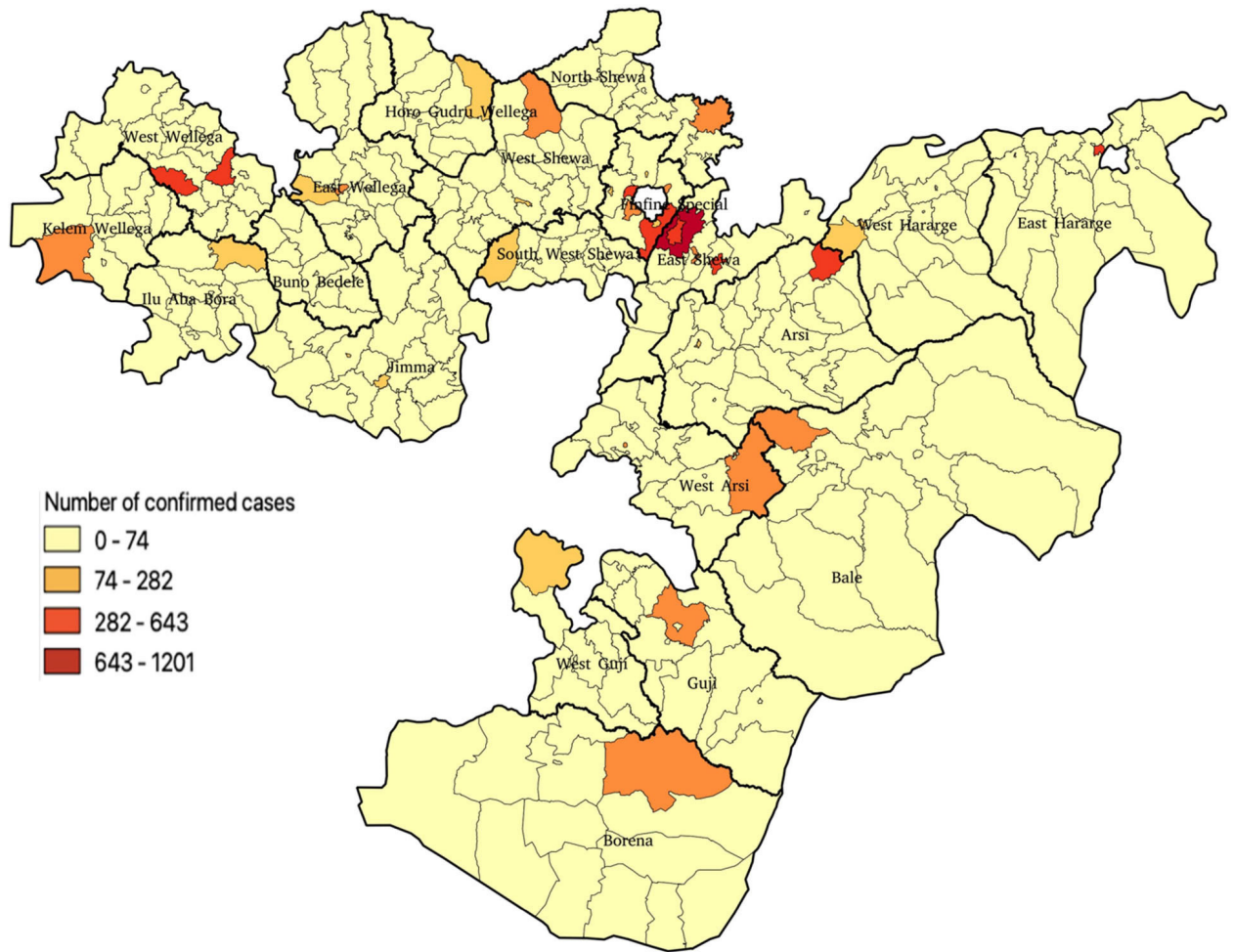

Figure 4 The geographical distribution of COVID-19 cases in Oromia Region, Ethiopia.

cases play an essential role in transmitting SARS-CoV-2 infection. ${ }^{41-43}$ The high rate of the asymptomatic case may thus create a 'mixed blessing.' An acute surge in the number of severe cases, hospital/intensive care unit admissions and deaths may not be observed. Nevertheless, the overall threat posed by the disease may be much more than perceived by the public and the healthcare system in the long run.

Fast spread of the disease and clustering of cases in overcrowded urban settings are well documented. ${ }^{44} 45$ Findings in our study are concordant with this. However, it is also possible that this clustering may be exaggerated as COVID-19 testing and surveillance systems are potentially limited to urban settings due to scarcity of the testing. ${ }^{46}$ Our finding is also notable for clustering of cases in those less than 50 years of age. Though COVID19-related deaths prominently occur in older people, ${ }^{47}$ there is no known age predilection for the infection of the virus. ${ }^{48}$ However, SARS-CoV-2 infections in Africa were reported mostly in younger individuals because of the predominantly younger population. ${ }^{49}{ }^{50}$ This in turn explains why COVID-19 is less severe and associated with relatively lower CFR in Africa. ${ }^{17}$

Ethiopia closed its land borders and started mandatory quarantine for international arrivals after reporting the first case in March. Presumably, this measure has minimised the number of imported cases. However, the disease was probably transmitting at high rate, as evidenced by the basic reproduction ratio of 8.7 for imported cases and 5.0 for close contacts. We thus believe that Oromia, and Ethiopia in general, avoided the expected catastrophe from the pandemic not because of the low disease transmission rate but most likely due to milder and asymptomatic cases as explained above. As cases with no or mild symptoms are less likely to seek treatment, silent community spread may lead to a late outbreak peak that entails difficult to contain. However, a sound prediction of the future pattern is challenged by limited laboratory testing and surveillance system.

\section{Strengths and limitations}

This study is the first comprehensive report on COVID-19 from Ethiopia. The epidemiological trends and clinical profile of cases have been presented. However, there are some limitations worth mentioning here. We did not include the clinical course during follow-up in this report as the surveillance database included only clinical status at diagnosis and discharge outcomes. Hence, patients who were asymptomatic during the initial diagnosis might have developed symptoms and severe disease later. As stated above, it is also highly likely that mild and non-specific symptoms might have been ignored by both the patients and the healthcare provider that could have underestimated the number of symptomatic cases. On the other hand, the reported CFR is likely to be inaccurate due to (1) the case definition used by the country for COVID-19-related deaths was non-selective and (2) many COVID-19-related deaths might have been missed due to poor surveillance system.

\section{CONCLUSION}

This surveillance report has shown that COVID-19 cases in Oromia Region are steadily increasing in recent months. 
However, symptomatic cases and severe diseases and the CFR are lower than most reports from other countries so far. While the very high asymptomatic and low fatality rates have prevented the healthcare system's feared crisis, it may be a hindrance to contain the outbreak. Even though active surveillance and widespread testing are essential to contain the outbreak, such approaches in settings with widespread community transmission and limited diagnostic facilities are challenging. Instead, the country should focus on averting COVID-19-related humanitarian crisis through strengthening and integrating COVID-19 surveillance into the health system and designing a better strategy to reduce mortality in vulnerable parts of the society, such as those with underlying medical conditions and the elderly. Moreover, a long-term national strategy to combat the pandemic should be based on periodic surveillance through seroprevalence studies.

\section{Author affiliations}

${ }^{1}$ Department of Internal Medicine, Jimma University Institute of Health, Jimma, Ethiopia

${ }^{2}$ Public Health Management and Health Research Directorate, Oromia Regional Health Bureau, Addis Ababa, Ethiopia

${ }^{3}$ Fenot Project, Department of Global Health and Population, Harvard University T H Chan School of Public Health, Addis Ababa, Ethiopia

${ }^{4}$ School of Medical Laboratory Sciences, Jimma University Institute of Health, Jimma, Ethiopia

${ }^{5}$ Disease Prevention and Health Promotion Directorate, Oromia Regional Health Bureau, Addis Ababa, Ethiopia

${ }^{6}$ Public Health Emergency Management and Health Research Directorate, Oromia Regional Health Bureau, Addis Ababa, Ethiopia

${ }^{7}$ Health Research Team Coordinator, Oromia Regional Health Bureau, Addis Ababa, Ethiopia

${ }^{8}$ Department of Reproductive Health and Population Studies, Bahir Dar University College of Medical and Health Sciences, Bahir Dar, Ethiopia

\section{Twitter Tizta Tilahun Degfie @Tizta_degfie}

Acknowledgements The authors would like to thank Oromia Region Health Bureau and its Public Health Emergency Management and Health Research Directorate for allowing them to use their surveillance data.

Contributors EKG, TTD, DG and TD analysed the data and drafted the manuscript. EKG, TTD, TG, DG, DY, TD, ZM and MW contributed to the conception and design of the work, to the acquisition and interpretation of data. DA, GS, BK, ML and DD contributed to conception of the work, and acquisition and interpretation of the data. All authors have reviewed the manuscript and approved the submitted version.

Funding The authors have not declared a specific grant for this research from any funding agency in the public, commercial or not-for-profit sectors.

Map disclaimer The depiction of boundaries on this map does not imply the expression of any opinion whatsoever on the part of BMJ (or any member of its group) concerning the legal status of any country, territory, jurisdiction or area or of its authorities. This map is provided without any warranty of any kind, either express or implied.

Competing interests None declared.

Patient and public involvement Patients and/or the public were not involved in the design, or conduct, or reporting, or dissemination plans of this research.

Patient consent for publication Not required.

Ethics approval The authors have obtained authorisation and approval to use the surveillance data from Oromia Regional Health Bureau Public Health Emergency Management and Health Research Directorate. They used only anonymised data for this analysis.

Provenance and peer review Not commissioned; externally peer reviewed.
Data availability statement Data are available upon reasonable request. The surveillance data on which this manuscript was based will be available upon request from the corresponding author after publication.

Open access This is an open access article distributed in accordance with the Creative Commons Attribution Non Commercial (CC BY-NC 4.0) license, which permits others to distribute, remix, adapt, build upon this work non-commercially, and license their derivative works on different terms, provided the original work is properly cited, appropriate credit is given, any changes made indicated, and the use is non-commercial. See: http://creativecommons.org/licenses/by-nc/4.0/.

\section{ORCID iDs}

Esayas Kebede Gudina http://orcid.org/0000-0002-6264-9695

Tizta Tilahun Degfie http://orcid.org/0000-0002-3842-9844

\section{REFERENCES}

1 World Health Organization. WHO coronavirus disease (COVID-19) dashboard.

2 Khattab NM, Vermund SH, Hu Y. How coronavirus disease 2019 entered Africa and the middle East: a case study from Egypt. Trans $R$ Soc Trop Med Hyg 2020;114:715-7.

3 Adepoju P. Nigeria responds to COVID-19; first case detected in subSaharan Africa. Nat Med 2020;26:444-8.

4 Massinga Loembé M, Tshangela A, Salyer SJ, et al. COVID-19 in Africa: the spread and response. Nat Med 2020;26:999-1003.

5 Ondoa P, Kebede Y, Loembe MM, et al. COVID-19 testing in Africa: lessons learnt. Lancet Microbe 2020;1:e103-4.

6 National Public Health Emergency Operation Center (PHEOC) of Ethiopia. COVID-19 Weekly Bulletin. Ethiopian Public Health Institute. https://www.ephi.gov.et/

7 Worldometer. COVID-19 coronavirus pandemic. Available: https:// www.worldometers.info/coronavirus/ [Accessed 15 Sep 2020].

8 Appleby J. What is happening to non-covid deaths? BMJ 2020;369:m1607.

9 Mahase E. Coronavirus covid-19 has killed more people than SARS and MERS combined, despite lower case fatality rate. BMJ 2020;368:m641.

10 Komarova NL, Schang LM, Wodarz D. Patterns of the COVID-19 pandemic spread around the world: exponential versus power laws. $J$ R Soc Interface 2020;17:20200518.

11 Gupta M, Wahl B, Adhikari B, et al. The need for COVID-19 research in low- and middle-income countries. Glob Health Res Policy 2020;5:33.

12 Casale M. COVID-19: can this crisis be transformative for global health? Glob Public Health 2020;15:1-13.

13 Roychowdhury D. Novel coronavirus disease, crisis, and isolation. Front Psychol 2019;2020:1958.

14 Allegrante JP, Auld ME, Natarajan S. Preventing COVID-19 and its sequela: "there is no magic bullet it's just behaviors". Am J Prev Med 2020;59:288-92.

15 Moti UG, Goon DT. Novel coronavirus disease: a delicate balancing act between health and the economy. Pak J Med Sci 2020;36:S134-7.

16 Boutaleb O. Africa is preparing for the worst against Coronavirus. In: South PCftN. 12. Rabat, Morocco, 2020.

17 Njenga MK, Dawa J, Nanyingi M, et al. Why is there low morbidity and mortality of COVID-19 in Africa? Am J Trop Med Hyg 2020;103:564-9.

18 Shepherd J, Friedland G. Preventing COVID-19 collateral damage. Clin Infect Dis2020.

19 Central Statistical Agency of Ethiopia. Population projections for Ethiopia 2007-2037. Addis Ababa, 2013.

20 World Health Organization. Public health surveillance for COVID-19: interim guidance, 2020.

21 Federal Ministry of Health of Ethiopia. National Comprensive COVID-19 management Handbook. Addis Ababa, 2020.

22 World Health Organization. Laboratory testing for coronavirus disease 2019 (COVID-19) in suspected human cases, 2020.

23 Ethiopian Public Health Institute. Interim national strategy and guidance for the laboratory diagnosis of COVID-19 in Ethiopia. Addis Ababa: EPHI, 2020.

24 World Health Organization. Estimating mortality from COVID-19. Available: https://www.who.int/news-room/commentaries/detail/ estimating-mortality-from-covid-19

$25 \mathrm{He}$ D, Zhao S, Lin Q, et al. The relative transmissibility of asymptomatic COVID-19 infections among close contacts. Int $J$ Infect Dis 2020;94:145-7. 
26 Cooper I, Mondal A, Antonopoulos CG. A SIR model assumption for the spread of COVID-19 in different communities. Chaos Solitons Fractals 2020;139:110057.

27 Ethiopian Public Health Institute. COVID-19 pandemic and emergency preparedness and response in Ethiopia: weekely bulletin. Available: https://www.ephi.gov.et/images/novel_coronavirus/ EPHI_PHEOC_COVID-19 Weekly-bulletin_1_English_05042020.pdf [Accessed 16 Sep 2020].

28 Nsubuga P, White ME, Thacker SB. Public health surveillance: a tool for targeting and monitoring interventions. In: Jamison DT, Breman JG, eds. Disease control priorities in developing countries. Washington, DC, 2006.

29 Huang C, Wang Y, Li X, et al. Clinical features of patients infected with 2019 novel coronavirus in Wuhan, China. Lancet 2020;395:497-506.

30 Wu Z, McGoogan JM. Characteristics of and important lessons from the coronavirus disease 2019 (COVID-19) outbreak in China: summary of a report of 72314 cases from the Chinese center for disease control and prevention. JAMA 2020;323:1239-42.

31 Day M. Covid-19: four fifths of cases are asymptomatic, China figures indicate. BMJ 2020;369:m1375.

32 Day M. Covid-19: identifying and isolating asymptomatic people helped eliminate virus in Italian village. BMJ 2020;368:m1165.

33 Kimball A, Hatfield KM, Arons M, et al. Asymptomatic and Presymptomatic SARS-CoV-2 Infections in Residents of a Long-Term Care Skilled Nursing Facility - King County, Washington, March 2020. MMWR Morb Mortal Wkly Rep 2020;69:377-81.

34 Sutton D, Fuchs K, D'Alton M, et al. Universal screening for SARS-CoV-2 in women admitted for delivery. $N$ Engl $J$ Med 2020;382:2163-4.

35 Dong Y, Mo X, Hu Y. Epidemiology of COVID-19 among children in China. Pediatrics 2020;145

36 Sharma AK, Ahmed A, Baig VN. Characteristics and outcomes of hospitalized young adults with mild Covid -19. J Assoc Physicians India 2020;68:62-5.

37 Sidiq KR, Sabir DK, Ali SM, et al. Does early childhood vaccination protect against COVID-19? Front Mol Biosci 2020;7:120.

38 Yitbarek K, Abraham G, Girma T, et al. The effect of Bacillus Calmette-Guérin (BCG) vaccination in preventing severe infectious respiratory diseases other than TB: implications for the COVID-19 pandemic. Vaccine 2020;38:6374-80.

39 Ssebambulidde K, Segawa I, Abuga KM. Parasites and their protection against COVID-19- ecology or immunology? medRxiv 2020.

40 Ghayda RA, Lee KH, Han YJ, et al. Estimation of global case fatality rate of coronavirus disease 2019 (COVID-19) using meta-analyses: comparison between calendar date and days since the outbreak of the first confirmed case. Int J Infect Dis 2020;100:302-308.

41 Yu X, Yang R. COVID-19 transmission through asymptomatic carriers is a challenge to containment. Influenza Other Respir Viruses 2020;14:474-5.

42 Rivett L, Sridhar S, Sparkes D, et al. Screening of healthcare workers for SARS-CoV-2 highlights the role of asymptomatic carriage in COVID-19 transmission. Elife 2020;9 doi:10.7554/ eLife.58728

43 Yin G, Jin H. Comparison of transmissibility of coronavirus between symptomatic and asymptomatic patients: reanalysis of the Ningbo COVID-19 data. JMIR Public Health Surveill 2020;6:e19464.

44 Ramírez-Aldana R, Gomez-Verjan JC, Bello-Chavolla OY. Spatial analysis of COVID-19 spread in Iran: insights into geographical and structural transmission determinants at a Province level. PLoS Negl Trop Dis 2020;14:e0008875.

$45 \mathrm{Li} \mathrm{B}$, Peng Y, He H, et al. Built environment and early infection of COVID-19 in urban districts: a case study of Huangzhou. Sustain Cities Soc 2021;66:102685.

46 Oladipo EK, Ajayi AF, Odeyemi AN, et al. Laboratory diagnosis of COVID-19 in Africa: availability, challenges and implications. Drug Discov Ther 2020;14:153-160.

47 Kang SJ, Jung SI. Age-Related morbidity and mortality among patients with COVID-19. Infect Chemother 2020;52:154-64.

48 Bulut C, Kato Y. Epidemiology of COVID-19. Turk J Med Sci 2020;50:563-70

49 Tinto B, Salinas S, Dicko A, et al. Spreading of SARS-CoV-2 in West Africa and assessment of risk factors. Epidemiol Infect 2020;148:e213.

50 Wang L, Dong S, Zhao Y, et al. Epidemic characteristics of COVID-19 in Africa. Front Phys 2020;8. 